
UNDER CONTRACT DE-AC02-76CH03073

PPPL-3785

PPPL-3785

UC-70

\title{
Exploration of High Harmonic Fast Wave Heating on the National Spherical Torus Experiment
}

\section{by}

J.R. Wilson, R.E. Bell, S. Bernabei, M. Bitter, P. Bonoli, D. Gates,

J. Hosea, B. LeBlanc, T.K. Mau, S. Medley, J. Menard, D. Mueller, M. Ono, C.K. Phillips, R.I. Pinsker, R. Raman, A. Rosenberg, P. Ryan, S. Sabbagh, D. Stutman, D. Swain, Y. Takase, J. Wilgen, and the NSTX Team

February 2003
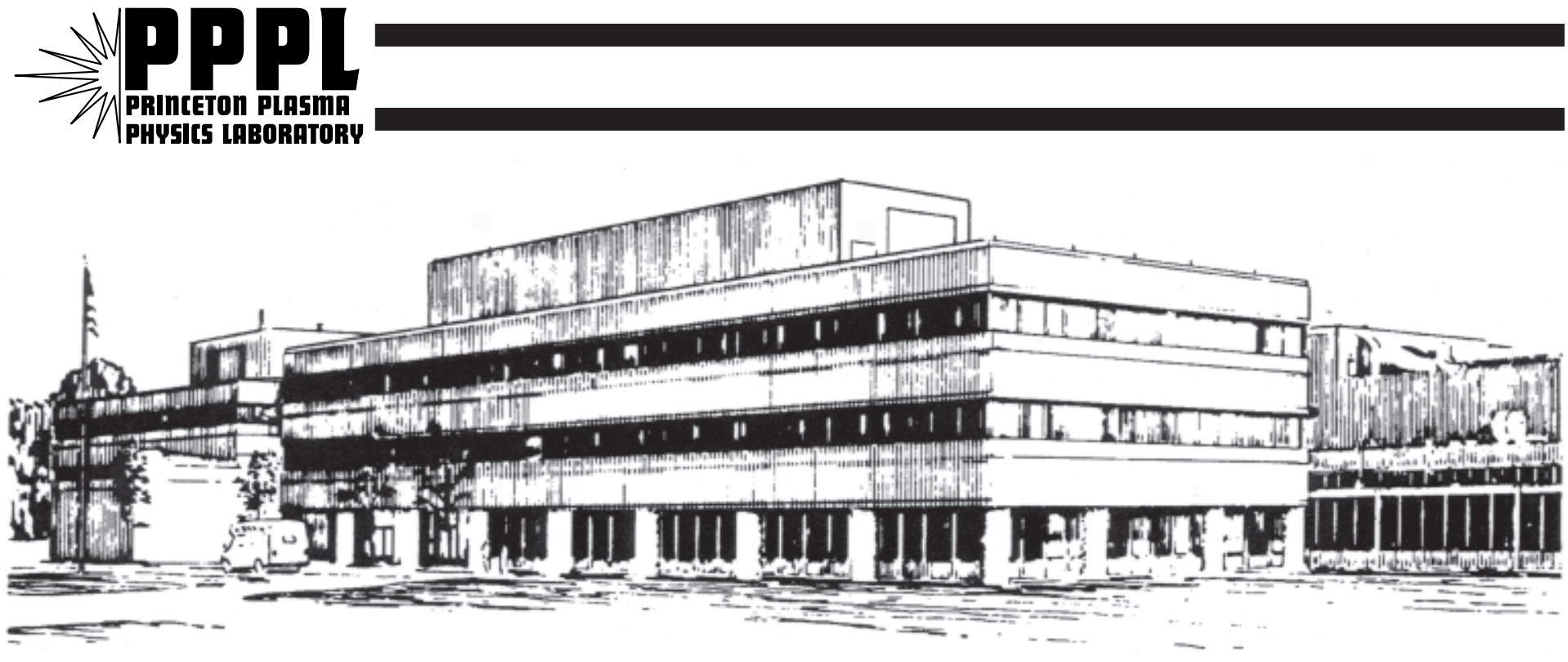

PRINCETON PLASMA PHYSICS LABORATORY PRINCETON UNIVERSITY, PRINCETON, NEW JERSEY 


\section{PPPL Reports Disclaimer}

This report was prepared as an account of work sponsored by an agency of the United States Government. Neither the United States Government nor any agency thereof, nor any of their employees, makes any warranty, express or implied, or assumes any legal liability or responsibility for the accuracy, completeness, or usefulness of any information, apparatus, product, or process disclosed, or represents that its use would not infringe privately owned rights. Reference herein to any specific commercial product, process, or service by trade name, trademark, manufacturer, or otherwise, does not necessarily constitute or imply its endorsement, recommendation, or favoring by the United States Government or any agency thereof. The views and opinions of authors expressed herein do not necessarily state or reflect those of the United States Government or any agency thereof.

\section{Availability}

This report is posted on the U.S. Department of Energy's Princeton Plasma Physics Laboratory Publications and Reports web site in Fiscal Year 2003. The home page for PPPL Reports and Publications is: http://www.pppl.gov/pub_report/

DOE and DOE Contractors can obtain copies of this report from:

U.S. Department of Energy

Office of Scientific and Technical Information

DOE Technical Information Services (DTIS)

P.O. Box 62

Oak Ridge, TN 37831

Telephone: (865) 576-8401

Fax: (865) 576-5728

Email: reports@adonis.osti.gov

This report is available to the general public from:

National Technical Information Service

U.S. Department of Commerce

5285 Port Royal Road

Springfield, VA 22161

Telephone: $1-800-553-6847$ or

(703) $605-6000$

Fax: (703) 321-8547

Internet: http://www.ntis.gov/ordering.htm 


\section{Exploration of high harmonic fast wave heating on the National Spherical Torus}

\section{Experiment}

J. R. Wilson, ${ }^{1, \dagger}$ R.E, Bell, ${ }^{1}$ S. Bernabei, ${ }^{1}$ M. Bitter, ${ }^{1}$ P. Bonoli, ${ }^{2}$ D. Gates,${ }^{1}$ J. Hosea,,${ }^{1}$ B. LeBlanc, ${ }^{1}$ T.K. Mau, ${ }^{3}$ S. Medley, ${ }^{1}$ J. Menard,${ }^{1}$ D, Mueller, ${ }^{1}$ M. Ono, ${ }^{1}$ C. K. Phillips,${ }^{1}$ R. I. Pinsker, ${ }^{4}$ R. Raman, ${ }^{5}$ A. Rosenberg, ${ }^{1}$ P. Ryan, ${ }^{6}$ S. Sabbagh, ${ }^{7}$ D. Stutman, ${ }^{8}$ D. Swain, ${ }^{6}$ Y. Takase, ${ }^{9}$ J. Wilgen, ${ }^{6}$ and the NSTX Team

Princeton Plasma Physics Laboratory, Princeton University, Princeton, NJ 08543

Massachusetts Institute of Technology, Cambridge MA 02139

University of California, San Diego, San Diego CA

General Atomics, San Diego CA 92186

University of Washington, Seattle WA 98105

Oak Ridge National Laboratory, Oak Ridge TN 37830

Dept. of Applied Physics, Columbia University, New York NY 10027

Johns Hopkins University, Baltimore MD

University of Tokyo, Tokyo, Japan

High Harmonic Fast Wave (HHFW) Heating has been proposed as a particularly attractive means for plasma heating and current drive in the high beta plasmas that are achievable in spherical torus (ST) devices. The National Spherical Torus Experiment (NSTX) [Ono, M., Kaye, S.M., Neumeyer, S., et al., Proceedings, $18^{\text {th }}$ IEEE/NPSS Symposium On Fusion Engineering, Albuquerque, 1999, (IEEE, Piscataway, NJ (1999), p. 53.] is such a device. An rf heating system has been installed on NSTX to explore the physics of HHFW heating, current drive via rf waves and for use as a tool to demonstrate the attractiveness of the ST concept as a fusion device. To date, experiments have demonstrated many of the theoretical predictions for HHFW. In particular, strong wave absorption on electrons over a wide range of plasma parameters and wave parallel phase velocities, wave acceleration of energetic ions, and indications of current drive for directed wave spectra have been observed. In addition HHFW heating has been used to explore the energy transport properties of NSTX plasmas, to create H-mode discharges 
with a large fraction of bootstrap current and to control the plasma current profile during the early stages of the discharge. 


\section{INTRODUCTION}

The mission of the National Spherical Torus Experiment ${ }^{1}$ (NSTX) includes the demonstration of non-inductive current generation and sustainment required for an attractive ST fusion device as well as exploration of the plasma physics of high $\square$, collisionless, toroidal plasmas at low aspect ratio. In order to achieve these goals auxiliary heating and current drive techniques are required to supplement the modest ohmic heating capabilities inherent in the ST concept. A high $\square$ plasma intrinsically has a high value of the plasma dielectric constant, $\square=\left(\square_{\mathrm{pe}} / \square_{\mathrm{ce}}\right)^{2}=\square_{\mathrm{e}}\left(\mathrm{c} / \mathrm{v}_{\mathrm{th}}\right)^{2}$, where $\square_{\mathrm{pe}}$ $=\left(4 \square \mathrm{n}_{\mathrm{e}}{ }^{2} / \mathrm{m}_{\mathrm{e}}\right)^{0.5}$ is the electron plasma frequency, $\square_{\mathrm{ce}}=\mathrm{eB} / \mathrm{m}_{\mathrm{e}} \mathrm{c}$ is the electron cyclotron frequency and $v_{\text {th }}$ is the electron thermal velocity. For NSTX this value is $\geq 50$. Conventional lower hybrid and electron cyclotron waves will not propagate at such large values of $\square$. While conventional fast wave Ion Cyclotron Range of Frequency (ICRF) heating is possible at high $\square$, High Harmonic Fast Wave (HHFW) heating $^{2}$ offered two attractive features for application on NSTX: First, it is attractive from the physics standpoint due to the large single pass damping decrement on the electrons with weak ion damping (allows the possibility of localized current drive); Second, it allowed the re-utilization of the rf equipment used for conventional ICRF experiments on the Tokamak Fusion Test Reactor (TFTR) ${ }^{3}$. To date experiments have validated the main ideas behind HHFW physics. Electron heating has been observed under a wide variety of conditions. Interaction of the rf wave with energetic ions has been observed while thermal ion heating has been minimal as predicted for the parameters so far achieved on NSTX. Evidence of current drive with directed spectra has been obtained from magnetic measurements, and application of HHFW 
power has allowed for an exploration of ST physics: H-modes, internal transport barriers (ITB) and the underlying energy transport mechanisms. In the main body of the paper we will give a brief overview of the basic theory behind HHFW physics, a description of the NSTX HHFW system and a summary of experimental results from NSTX.

\section{THEORY OF HHFW HEATING}

The basic theory for HHFW heating of high $\square$ plasmas was elucidated by $\mathrm{Ono}^{2}$. The wave used for HHFW remains the fast magnetosonic wave used for conventional ICRF. Because of the large harmonic number (in these NSTX experiments, $9<\square / \square_{\mathrm{i}}<13$ ) the thermal ion cyclotron damping can be quite weak while the electron damping can be strong.

When $\square \gg>\square_{i}$ and $\square_{\mathrm{e}}$ is substantial the damping of the wave on electrons is increased above that found in conventional fast wave direct electron heating experiments $^{4}$ for two reasons. First, The Transit Time magnetic pumping (TTMP) term from the yy component of the dielectric tensor no longer exactly cancels the cross, yz, term as found by Porkolab ${ }^{5}$ for conventional fast wave applications. Second, the ratio of the imaginary part of the wave number to the real part (damping per unit wavelength), which is proportional to $\square \square / \square_{i}$, increases for both larger values of beta and harmonic number. The increase in damping per unit wavelength is coupled with an increased number of wavelengths, $\mathrm{k}_{\square \mathrm{r}} \sim \square / \mathrm{v}_{\mathrm{A}} \quad \mathrm{n}_{\mathrm{e}}^{0.5 / \mathrm{B}}$, present for the same size plasma. These effects lead to a significant increase in the per pass damping of HHFW 
waves so that, unlike ICRF direct electron damping rates of $<15 \%$ per pass, it is not unusual to expect $100 \%$ damping in a single pass through the NSTX plasma. This is the most significant difference between HHFW and conventional fast wave electron heating. In fact, since the damping is so strong at high $\square$, the wave power can be significantly damped before it reaches the center of the plasma. This feature, in contrast to the always centrally peaked direct electron damping in conventional ICRF as applied to moderate beta tokamak plasmas, allows for the possibilities of off-axis current drive and radial deposition control via control of the launched wave spectrum.

Ion damping is weak at low ion temperature since cyclotron absorption for small $\mathrm{k}_{\text {perp }} \square_{\mathrm{i}}$ is proportional to $\square^{\mathrm{n}-1}$ where $\square=\left(\mathrm{k}_{\text {perp }} \square_{\mathrm{i}}\right)^{2} / 2$ and $\mathrm{n}$ is the cyclotron harmonic number. In NSTX damping on energetic ions from neutral beam injection (NBI) can be important since $\square>1$ and the absorption approaches the un-magnetized plasma limit from perpendicular ion landau damping and is proportional to $\mathrm{T}_{\text {hot }}{ }^{-3 / 2}$.

\section{DESCRIPTION OF THE NSTX HHFW SYSTEM}

The NSTX HHFW system features a twelve-element antenna, six rf transmitters, transmission system and a power dividing and decoupling network ${ }^{6}$.

A. The antenna consists of twelve identical modules each comprised of a solid copper radiating element fed at one end and grounded at the other to the 
antenna back plane, a 50\% transparent Faraday shield and a protective surround. The antenna module is shaped to poloidally conform to the plasma. The Faraday screen is composed of individual molybdenum U-shaped pieces, which are mechanically attached to the slotted side-walls of the antenna box. The antenna surround is composed of boron nitride plates mechanically mounted into holders. The surround provides an insulating surface for plasma scrape-off that should minimize rf driven sheath formation. Each antenna element has its own coaxial rf vacuum feedthrough,

B. The six rf transmitters are tuned to a fixed frequency of $30 \mathrm{MHz}$ and are rated for NSTX purposes at $1 \mathrm{MW}$ delivered power for $5 \mathrm{~s}$. The amplitude and phase of each amplifier are individual controllable. The phase velocity of the launched rf wave is controlled by varying the phase relationship between the transmitters. A sample of the rf voltage is taken near the vacuum feedthrough and used in a digital phase feedback system to provide this phase control. The phase can be varied during the shot to reproduce a pre-programmed waveform.

C. Since there are twelve antenna elements and only six transmitters the rf power must be divided to feed the antenna. In addition, the degree of phase control required to achieve the desired antenna spectra requires cancellation of the mutual inductance between the antenna elements. To accomplish both of these tasks a network of precision tuned transmission lines and lumped reactive elements is placed between the transmitters and the antenna. A schematic of this arrangement is shown in Fig. 1. This network divides the 
power from each transmitter into two lines and applies then to the $\mathrm{i}^{\text {th }}$ and $\mathrm{i}^{\text {th }}+6$ $(1<\mathrm{i}<6)$ antenna element. Since this is done by means of resonant lengths of transmission line the phase between these pairs of antenna elements is a fixed $180^{\circ}$. Shunt transmission line connections (elements D1-D6 in Fig. 1) between each pair of transmitters cross couple power with the precise amplitude and phase relationship required to cancel the nearest neighbor mutual inductance of the antenna array. This cancellation is sufficient to allow the desired external phase control during plasma operation. A residual nextnearest neighbor mutual remains, which prevents complete phase control during vacuum conditioning. Impedance matching between the transmitters and the antenna decoupling system is accomplished with standard quarter wave transformers and adjustable line stretchers and tuning stubs, all in 9-inch coaxial transmission line.

\section{RESULTS OF NSTX HHFW EXPERIMENTS}

The HHFW experiments on NSTX have set out to elucidate the physics of HHFW wave propagation and absorption and to utilize HHFW as a tool for ST physics exploration. Coupling of the HHFW wave from the antenna array to the plasma is expected to be similar to that for conventional tokamaks. The antenna radiation resistance should be larger due to the shorter radial wavelength and the lower cutoff density in the plasma edge, $\mathrm{n}_{\text {cutoff }} \quad \square_{\mathrm{i}} / \square$ and this is observed. The radiation resistance decreases as the plasma antenna gap is increased in agreement with expectations. If the gap is increased 
too far, greater than $\sim 15 \mathrm{~cm}$, the effectiveness of the $\mathrm{rf}$ heating is reduced even though the density is still above cutoff near the antenna. Initial experiments concentrated on establishing the absorption characteristics for the wave. NSTX target plasmas having a range of plasma parameters have been investigated: $\mathrm{B}_{\mathrm{T}}\left(\mathrm{R}_{0}\right)=0.3-0.5 \mathrm{~T}, \mathrm{I}_{\mathrm{p}}=0.3-0.9 \mathrm{MA}$, $<\mathrm{n}_{\mathrm{e}}>=0.3-3.8 \times 10^{19} \mathrm{~m}^{-3}, \mathrm{~T}_{\mathrm{e}}(0)=200-700 \mathrm{eV}$. Both ${ }^{4} \mathrm{He}$ and $\mathrm{D}$ plasmas have been investigated in limiter and divertor configurations. It was quickly observed that electron heating was the dominant effect as predicted by theory. Heating has been observed for a range of launched toroidal wave numbers, $\mathrm{k}_{\square}=3-14 \mathrm{~m}^{-1}$. At $\mathrm{k}_{\square}=14 \mathrm{~m}^{-1}$, utilizing waves with the slowest toroidal phase velocity, heating has been observed with target temperatures as low as $200 \mathrm{eV}$, (Fig. 2). This demonstrates that even at low beta the single pass absorption must be great enough to dominate over parasitic damping processes. As the launched parallel wavelength is increased the central electron temperature increases more slowly in time but reaches comparable values. This agrees with theoretical scaling of weaker initial absorption at lower $\mathrm{k}_{\|}$. To check the theoretical prediction that the electron absorption should move off axis as the target plasma electron beta is increased it would be desirous to have a direct measurement of the power deposition profile. Normally, this would be achieved by modulating the rf power and measuring $\mathrm{T}_{\mathrm{e}}(\mathrm{r}, \mathrm{t})$ with a fast electron temperature diagnostic such as electron cyclotron emission (ECE) and then performing either break in slope or Fourier analysis of the signals. In an ST ECE cannot be used because of lack of accessibility of the waves from the plasma core to the edge. On NSTX a multi-point repetitive Thomson scattering system is used to obtain the electron temperature profile. This system utilizes two independent $33 \mathrm{~Hz}$ lasers whose relative timing can be adjusted. An attempt to measure 
the electron temperature response to a fast change in the rf power level was made by varying the time between laser measurements. It was found that the electron temperature profile was very "stiff" with little immediate response to the removal of power followed by a general relaxation of the temperature profile. This is consistent with theoretical predictions that electron temperature gradient modes determine the electron heat loss. Some indication of off-axis absorption occurs in shots with higher electron beta by the presence of broader $T_{e}$ profiles during the rf heating. Future experiments with tangential soft x-ray cameras may allow a more continuous measurement of the electron response and provide insight into the deposition profile. Global energy confinement in discharges with electron heating is in agreement with predictions from standard L-mode scalings.

Large increases in central electron temperature are obtained in specific cases of HHFW heating; $I_{p}=800 \mathrm{kA}$ deuterium plasmas at moderate density. These discharges are characterized by a central region, $\mathrm{r} / \mathrm{a} \leq 0.5$, in which the electron transport is much reduced. Peaked temperatures as high as $4 \mathrm{keV}$ are obtained in these discharges with $\square_{e}$ reduced by as much as a factor of 10 in the core as the barrier develops.

The principal motivation for including the HHFW system on NSTX was the desire to produce non-ohmic current drive to demonstrate the potential of the ST concept as a steady-state plasma device. Current drive with direct electron absorption has been observed on variety of devices, in particular operation at cyclotron harmonic numbers as high as eight was explored on the DIII-D tokamak ${ }^{7}$. Experiments on NSTX were conducted at harmonic numbers 9-12 where thermal ion absorption should be minimal. In addition electron beta values on NSTX should allow much higher single pass damping values. The low aspect ratio of NSTX, R/a=1.25, strongly influences the wave 
propagation (the waves develop much larger values of $\mathrm{k}_{\square}$ and can fail to propagate all the way to the center of the discharge) and reduces the driven current due to the increased fraction of trapped electrons. Experiments have been conducted on NSTX to make a preliminary assessment of the viability of HHFW current drive. In the absence of a Motional Stark effect (MSE) diagnostic to measure local changes in the magnetic field the experiments were designed to maximize the expected changes in loop voltage that would arise from driving current. To maximize the expected loop voltage changes and minimize the interference from bootstrap current effects these experiments were conducted at low current, $\mathrm{I}_{\mathrm{p}}=500 \mathrm{kA}$, and low $\mathrm{Q}$, less than 10 percent. Discharges with the rf antenna phased to drive current with, Co, and against, Counter, the pre-existing ohmic current were executed. The observed loop voltage was seen to be very sensitive to the electron density and temperature obtained during the rf pulse. Power levels were adjusted to obtain equal temperatures and gas fueling was adjusted to obtain near equal density profiles, (Fig. 3). Under these conditions differences in the loop voltages between co-, $\mathrm{k}_{\square}=+7 \mathrm{~m}^{-1}$, and counter, $\mathrm{k}_{\square}=-7 \mathrm{~m}^{-1}$, phased discharges were obtained, (Fig. 4). The time evolution of the differences indicate that as central magneto-hydrodynamic activity (MHD), sawtooth like behavior, sets in, the amount of driven current appears to diminish. If strong central MHD is present before the rf is applied no loop voltage difference is observed. As was observed on DIII-D less power is needed for counter-phasing than for co-phasing to obtain the same central electron temperature. This difference in required power decreases at lower $k_{\square}$. To estimate the current driven in this case we perform a simple circuit calculation assuming that the discharges have the same resistivity, matching the temperature, density and $Z_{\text {eff }}$ gives reasonable confidence that this is true, 
and taking into account the change in internal inductance. The observed loop voltage difference of $0.22 \mathrm{~V}$ corresponds to $\sim 180 \mathrm{kA}$ of driven current, $110 \mathrm{kA}$ co and $70 \mathrm{kA}$ counter. Theoretical estimates for these discharges have been made using both the CURRAY $^{8}$ ray tracing code (169 kA co and $79 \mathrm{kA}$ counter) and the TORIC $^{9}$ full wave analysis code (96 kA co and 50 counter). These estimates point out the importance of trapping in determining the efficiency of current drive. With the effects of trapping turned off TORIC predicts nearly $400 \mathrm{kA}$ of current would be driven, (Fig. 5). The efficiency of current drive is given in terms of a figure of merit, $\square_{\mathrm{D}}=0.05 \times 10^{19} \mathrm{Am}^{-2} / \mathrm{W}$, comparable to that observed on previous experiments given the lower electron temperature ${ }^{7,10,11}$. The normalization for temperature has been given by DIII-D as $\square_{C D}=Z_{C D} * 3.27 / T_{e}(0)$. For NSTX $\square_{C D}=0.15$. The best current drive efficiencies on DIII-D were higher and parasitic absorption on the neutral beam ions was blamed for lower efficiency shots. This should not be the case for these NSTX discharges. Trapping, however, will play a stronger role at the lower aspect ratio of NSTX. In addition, if wave absorption is not single pass, as is the case in these low $\square$ discharges, and the edge density is high enough such that the low field side cut-off is in the plasma periphery, loss of rf power due to waves not reflecting off the low field side cut-off is possible. This effect was invoked to explain some lower efficiency shots on DIII-D. On NSTX the low field side cut-off is always in the plasma periphery and in lower single pass conditions such as those for these particular discharges the wave trajectories touch the low field edge several times before all the power is expected to damp. If the wave is approaching the edge near a material object, e.g. a passive plate or neutral beam armor, an rf sheath might form which can dissipate if power. 
Absorption of the HHFW wave energy by energetic ions presents a parasitic mechanism that can reduce current drive efficiency. In NSTX's most recent campaign, a clear fast ion tail was observed on the neutral particle analyzer (NPA) when HHFW and neutral beam injection (NBI) were active simultaneously. Neutron detector and ion loss probe signals provided further evidence for interaction. This occurred for essentially every shot in which there was a significant overlap in rf and NBI power. Ray-tracing was used to analyze these shots, and absorption by fast ions was found to be competitive with electron absorption. Measured neutron rates for similar rf and no-rf shots were also compared with predicted rates, and a significant rf-induced enhancement was found, qualitatively consistent with the presence of an enhanced ion energy distribution.

For most shots analyzed, the neutral beam injected deuterium into the plasma at $\mathrm{E}_{\mathrm{b}} \square 80 \mathrm{keV}, \mathrm{P}_{\mathrm{b}} \square 1.6 \mathrm{MW}$. Without $\mathrm{rf}$, the energy spectrum observed by the NPA dropped out above $\sim 80 \mathrm{keV}$. With rf, the energy spectrum extended to $\sim 140 \mathrm{keV}$. Furthermore, after rf turnoff with NBI remaining active, the tail decayed to the no-rf spectrum on a time scale comparable to that for decay of a beam-only distribution, as seen in Fig 6.

The $\mathrm{ZnS}$ and fission neutron detectors also saw a significant signal enhancement with rf, which also began dropping immediately upon rf turnoff. Sets of similar shots with different $\mathrm{B}_{0}, \mathrm{I}_{\mathrm{p}}, \mathrm{E}_{\mathrm{b}}$, and launched $\mathrm{k}_{\|}$were examined. In agreement with modeling, the tail strength and neutron rate at lower B-fields were observed to be less enhanced, likely due to a larger value of $\square$, which promotes greater off-axis electron absorption where the fast ion population is small. Tail strength also increased with higher beam energy, and a substantial neutron rate enhancement was observed at higher $\mathrm{I}_{\mathrm{p}}$. Though 
greater ion absorption is predicted with lower $\mathrm{k}_{\|}^{12,13}$, surprisingly little variation in the tail was observed, along with a small neutron enhancement with higher $\mathrm{k}_{\|}$. The NPA was also scanned horizontally, and flux of fast particles decreased as the tangency radius moved away from the magnetic axis, while the energy range of the tail remained the same for tangency radii up to $40 \mathrm{~cm}$ off axis. In addition to the NPA and neutron detectors, ion loss probes at $\mathrm{R}=163 \mathrm{~cm}$ and $166 \mathrm{~cm}$ saw a signal enhancement with $\mathrm{RF}$ on in beam shots.

For analysis, the TRANSP transport analysis code was used to calculate fast ion energy and particle density profiles, and this information was used to estimate an effective Maxwellian temperature, $\mathrm{T}_{\mathrm{f}}$, for the fast ion population. This, along with EFIT and Thomson data, was fed into HPRT, a 2-D ray-tracing code ${ }^{13}$, which uses the full hot plasma dielectric to compute power deposition profiles along the hot electron/cold ion ray path. Fast ion absorption was calculated to be quite competitive with electron absorption in sustained neutral beam shots, often taking $\sim 40 \%$ of the total $\mathrm{rf}$ power. These results and profiles matched those of CURRAY, an independently developed ray-tracing code, strikingly well. AORSA ${ }^{14}$, an all orders full wave code, also found a similar power split using analytic approximations to the above data. Without providing rf input in either case, TRANSP was also used to calculate the neutron rates for similar rf and no-rf shots. The measured rate matched the prediction well in the no-rf case, and for the rf shot grew to nearly double the predicted rate. It then decayed to approximately the computed rate after rf turnoff. 


\section{SUMMARY}

Experiments to investigate the physics of HHFW heating and current drive in an ST geometry have been carried out on the NSTX device. As expected from theoretical modeling the rf power is absorbed almost entirely by the electrons for the parameters of the NSTX experiment, when neutral beam injection is absent. Global energy confinement for discharges heated via the electron channel is in reasonable agreement with the predictions of standard tokamak scaling. Under some circumstances improved electron energy confinement is observed and central electron temperatures of $4 \mathrm{keV}$ have been achieved.

In initial experiments with the antenna phased to launch a toroidally directed spectrum, differences in loop voltage have been observed consistent with plasma current being driven by the wave. The value of current driven, inferred from the magnetic measurements, is $\sim 100 \mathrm{kA}$ and is roughly consistent with theoretical estimates. To achieve larger quantities of driven current both higher rf power and higher electron temperatures will be required.

Experiments with combined HHFW and NBI reveal an acceleration of the beam ions by the rf. An ion tail extending, from the $80 \mathrm{keV}$ injection energy out to $140 \mathrm{keV}$, is observed. This ion absorption which modeling predicts could absorb as much as $50 \%$ of the rf power will lower current drive efficiency. The absorption is predicted and observed to be lower at higher $\square$.

\section{ACKNOWLEDGEMENTS}

This work supported by United States Department of Energy Contract Numbers 
DE-AC02-76CH03073 at the Princeton Plasma Physics Laboratory, DE-AC0596OR22464 at the Oak Ridge National Laboratory, DE-FG02-99ER-54521 at MIT, DEFG06-90ER54095 at the University of Washington, DE-FG02-89ER53297 at Columbia University and DE-AC03-99ER54463 at General Atomics. 


\section{REFERENCES}

1. Ono, M., Kaye, S.M., Neumeyer, S., et al., Proceedings, $18^{\text {th }}$ IEEE/NPSS

Symposium On Fusion Engineering, Albuquerque, 1999, (IEEE, Piscataway, NJ (1999), p. 53.

2. Ono, M., Phys. Plasmas 2, 4075 (1995).

3. Grove, D.J. and Meade, D.M., Nucl. Fusion 25, 1167 (1985).

4. Petty, C., Pinsker, R.I., Mayberry, M.J., et al., PRL 69, 289 (1992).

5. Porkolab, M., Proceedings of the $9^{\text {th }}$ Topical Conference on Radio Frequency Power in Plasmas, Charleston SC, 1991, edited by D. Batchelor (American Institute of Physics, New York, 1992), p. 197.

6. Ryan, P.M., Wilson, J.R., Swain, D.W., et al., Fusion Eng. Design 56-57, 569 (2001).

7. Petty, C., Baity, F.W., deGrassie, J.S., et al., Plasma Phys. Contr. Fusion 43, 1747 (2001).

8. Mau, T.K., LeBlanc, B., Menard, J., et al., Proceedings of the $14^{\text {th }}$ Topical Conference on Radio Frequency Power in Plasmas, Oxnard CA, 2001, edited by T. K Mau and J. deGrassie (American Institute of Physics, New York, 2001), p. 170.

9. Brambilla, M., Plasma Phys. Contr. Fusion 41, 1 (1999).

10. Rogers, J., Hosea, J.C., LeBlanc, B., et al., Proceedings, $16^{\text {th }}$ International Conference On Fusion Energy, Montreal Canada, 1996, (IAEA, Vienna 1997), Vol. 3 p. 317.

11. Majeski, R., Rogers, J.H., Batha, S.H., et al., PRL 76, 764 (1996). 
12. Lashmore-Davies, C.N., Fuchs, V., Cairns, R.A., Phys. of Plasmas 5, 2284 (1998).

13. Menard, J., Majeski, R., Kaita, R., et al., Phys. of Plasmas 6, 2002 (1999).

14. Jaeger, E.F. Berry, L.A., d'Azvedo, E., et al., Proceedings of the $14^{\text {th }}$ Topical Conference on Radio Frequency Power in Plasmas, Oxnard CA, 2001, edited by T. K. Mau and J. deGrassie (American Institute of Physics, New York, 2001), p. 369. 


\section{FIGURE CAPTIONS}

Fig. 1 Schematic diagram of the rf distribution system showing the twelve antenna elements, the six rf inputs $\left(\mathrm{T}_{1}-\mathrm{T}_{6}\right)$ and the splitting decoupling network (D1-D6).

Fig. 2 Electron heating on NSTX (a) Time evolution of the electron temperature, plasma current and rf and NBI power. The NBI is in short blips to get the ion temperature via charge exchange recombination spectroscopy. (b) The electron and ion temperature profiles at $\mathrm{t}=0.25 \mathrm{~s}$.

Fig.3 The time evolution of the electron temperature and density for Co (solid) and Counter (dashed) current drive phasing of the rf.

Fig. 4 Time evolution of the loop voltage for Co and Counter phasing for the same discharges as in Fig. 3.

Fig. 5 Theoretical driven current profile with and without trapping for the Co current drive shot in Fig. 3 as predicted by the TORIC wave code. The profile is significantly narrower with trapping effects turned on.

Fig. 6 Neutral particle charge exchange flux as a function of energy showing the decay of the tail above the $80 \mathrm{keV}$ injection energy after the turnoff of $\mathrm{rf}$. 
RF Transmitters

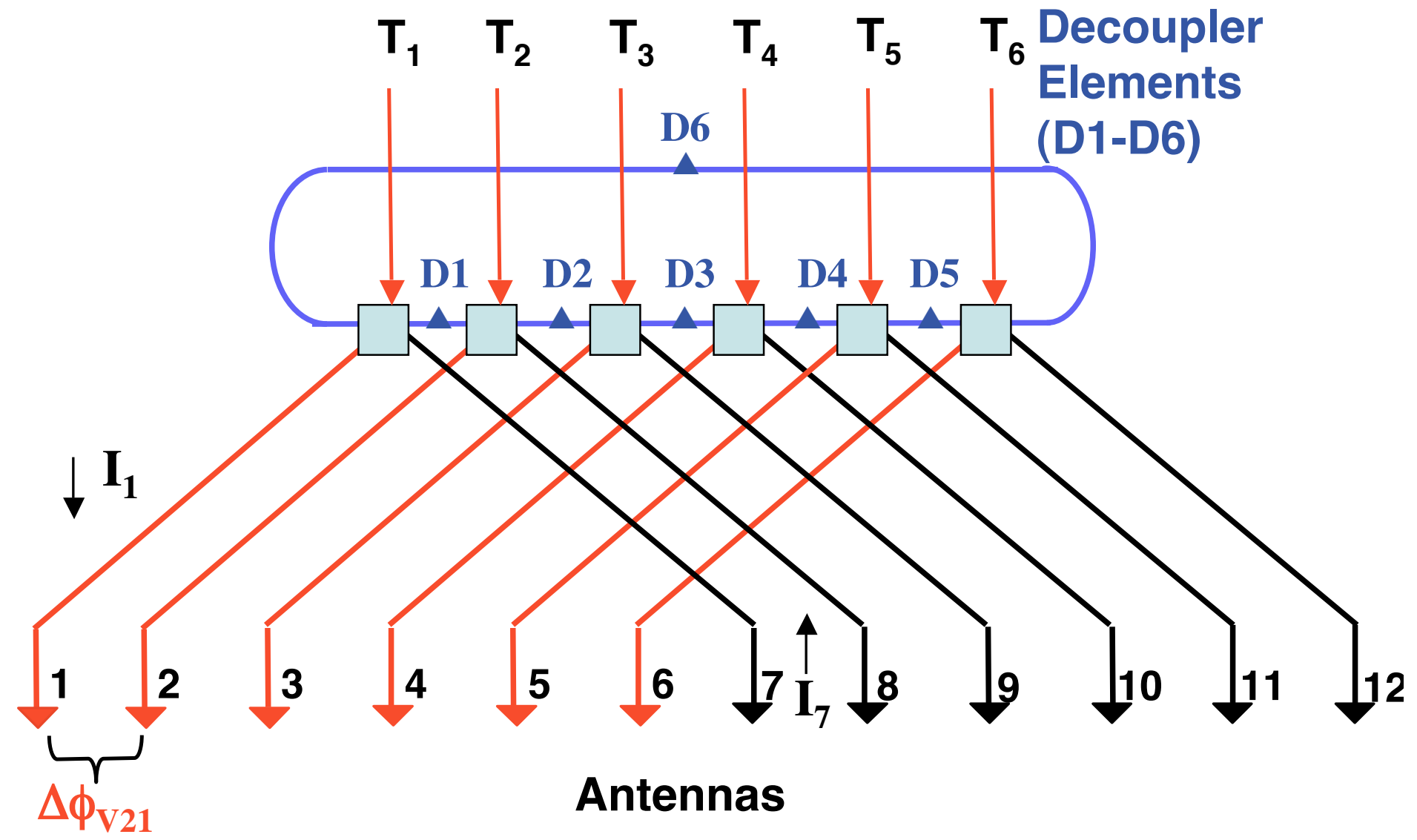

Figure1 

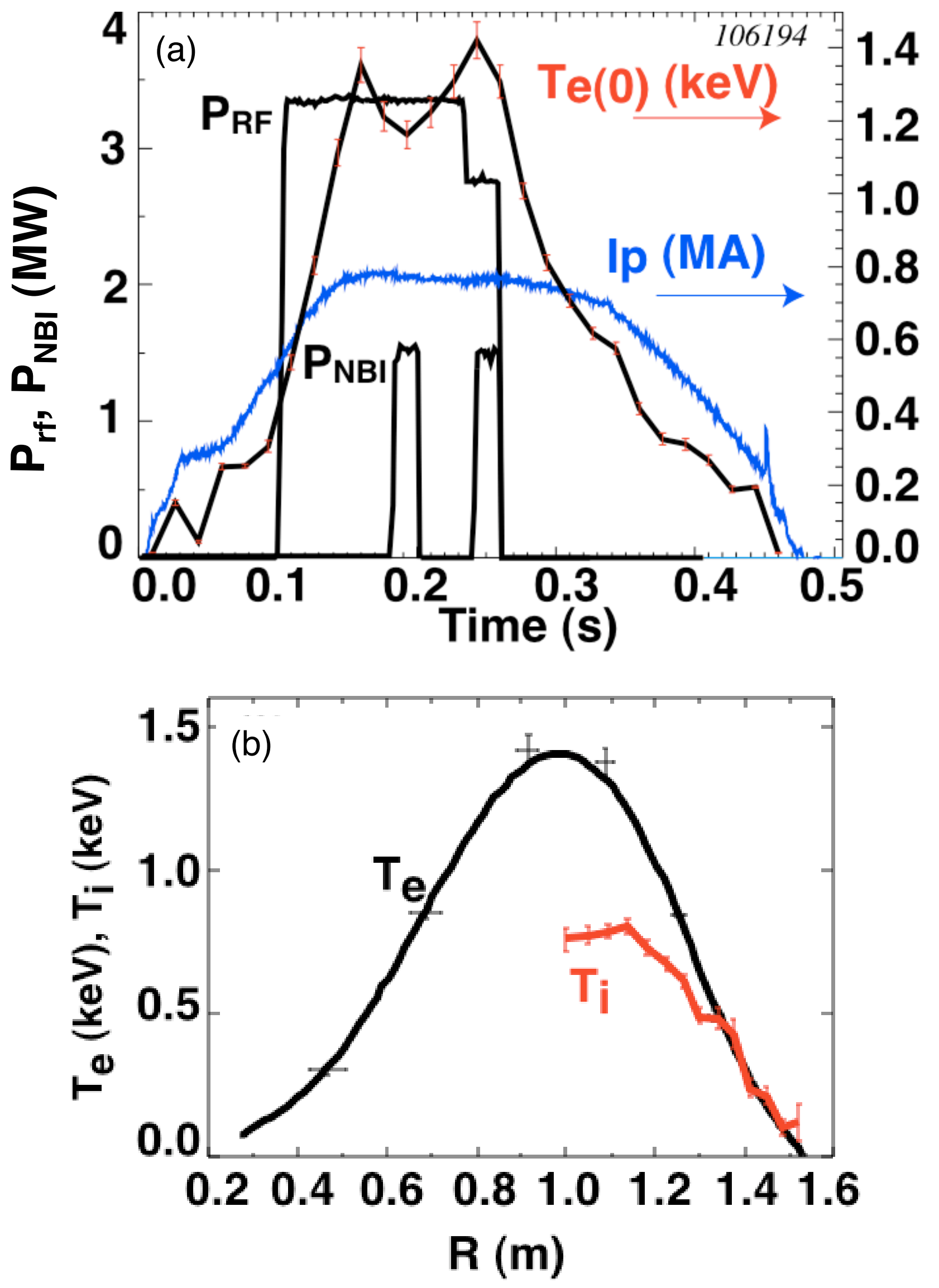

Figure 2 


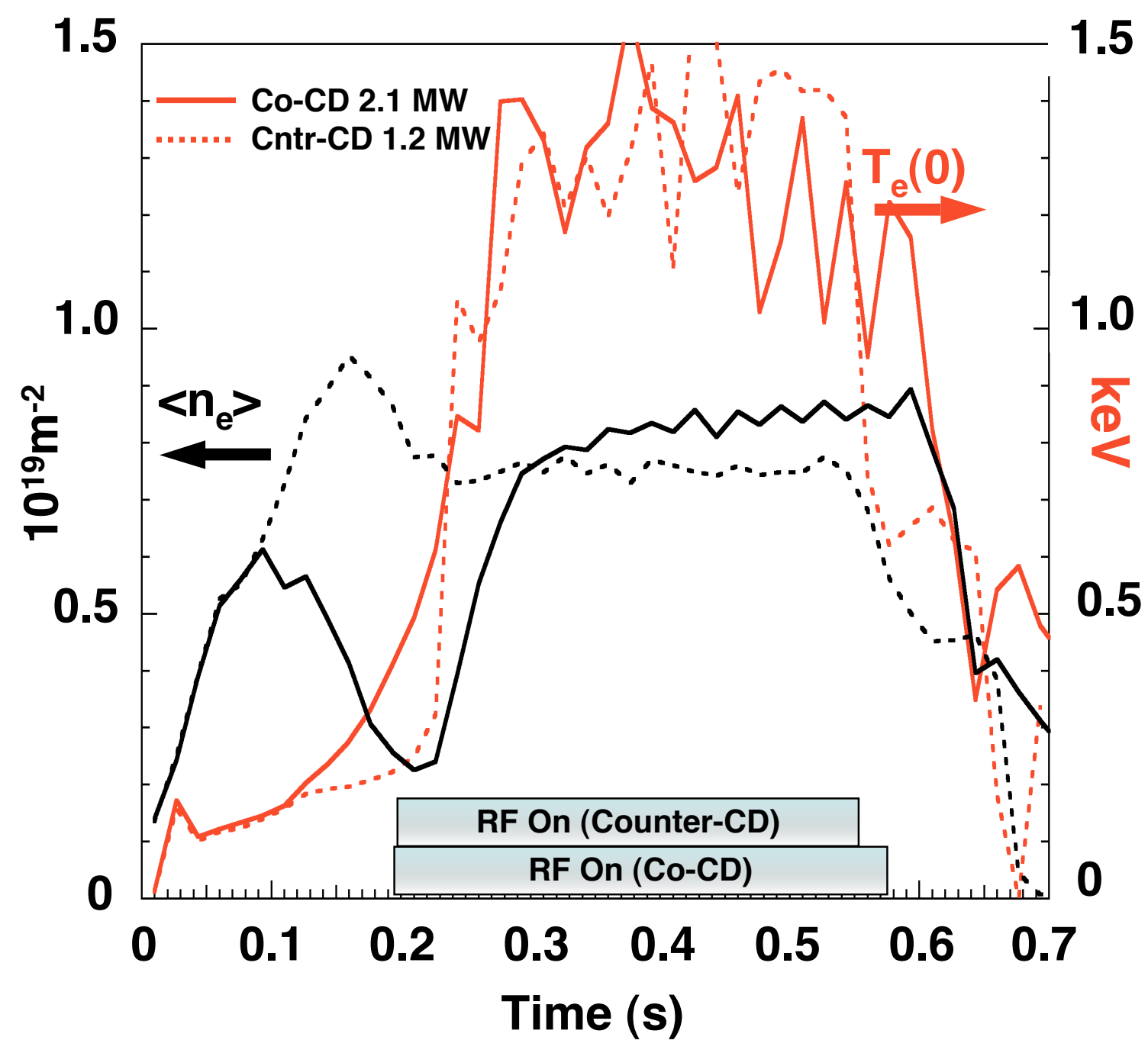

Figure3 


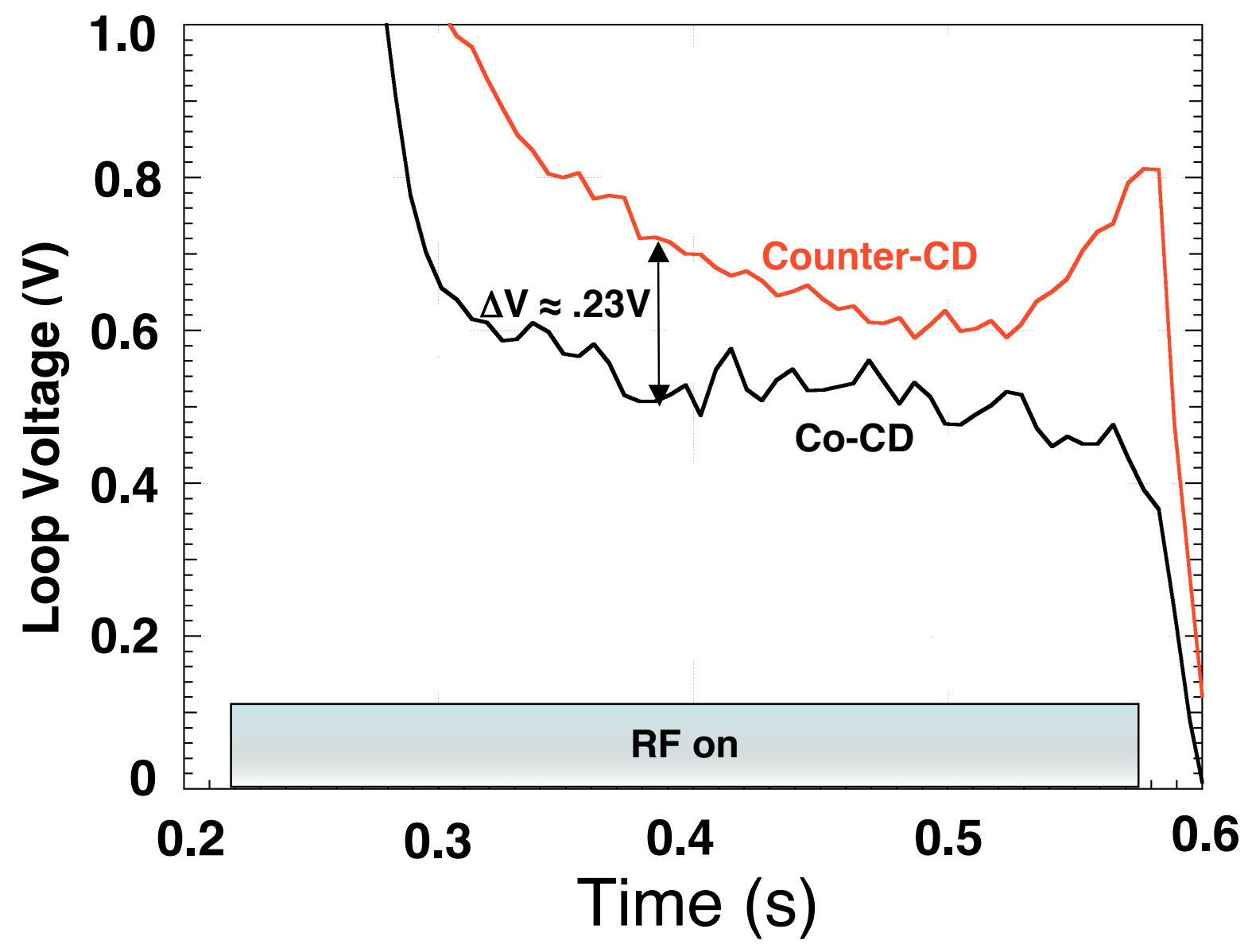

Figure 4 


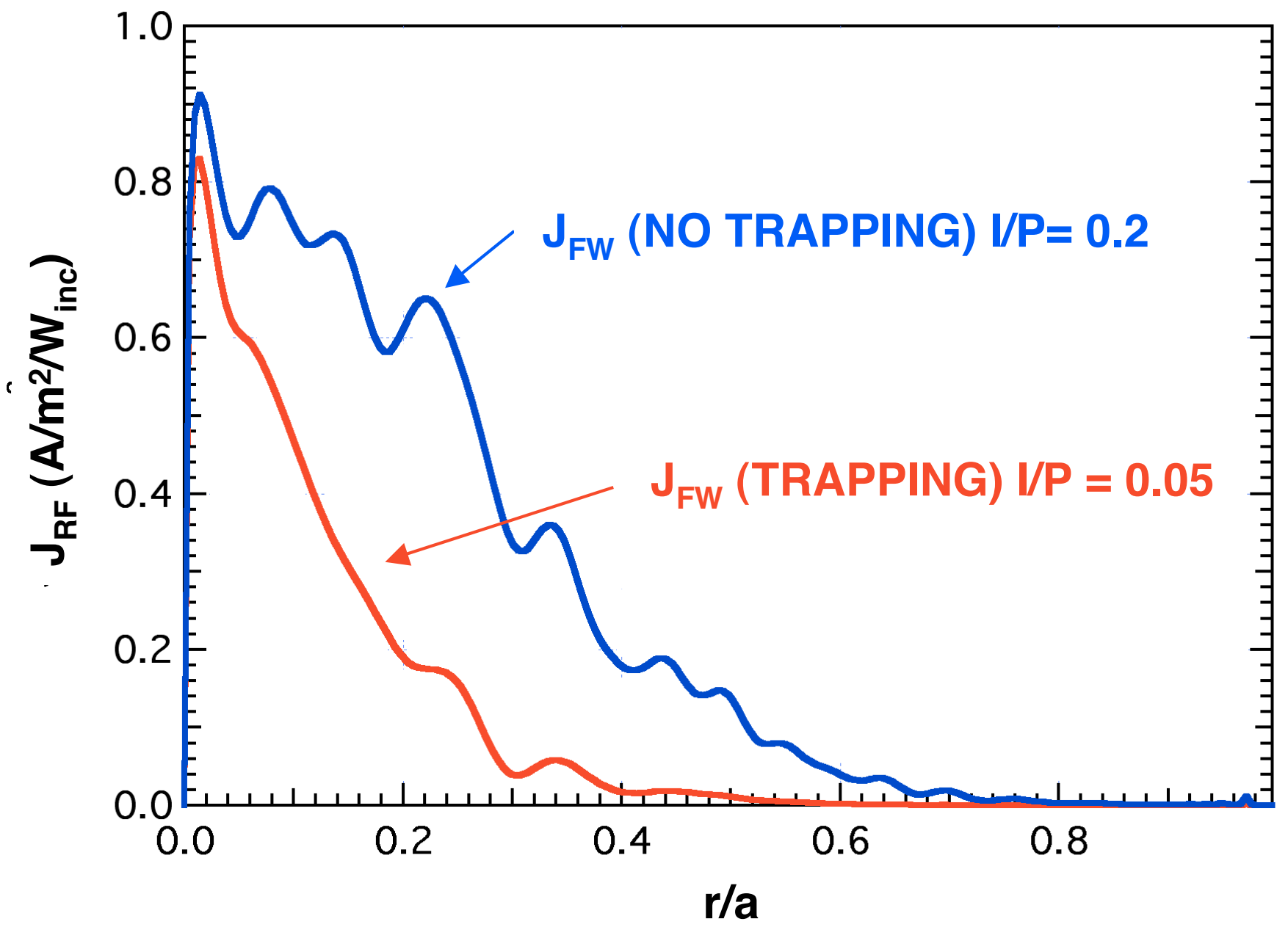

Figure5 


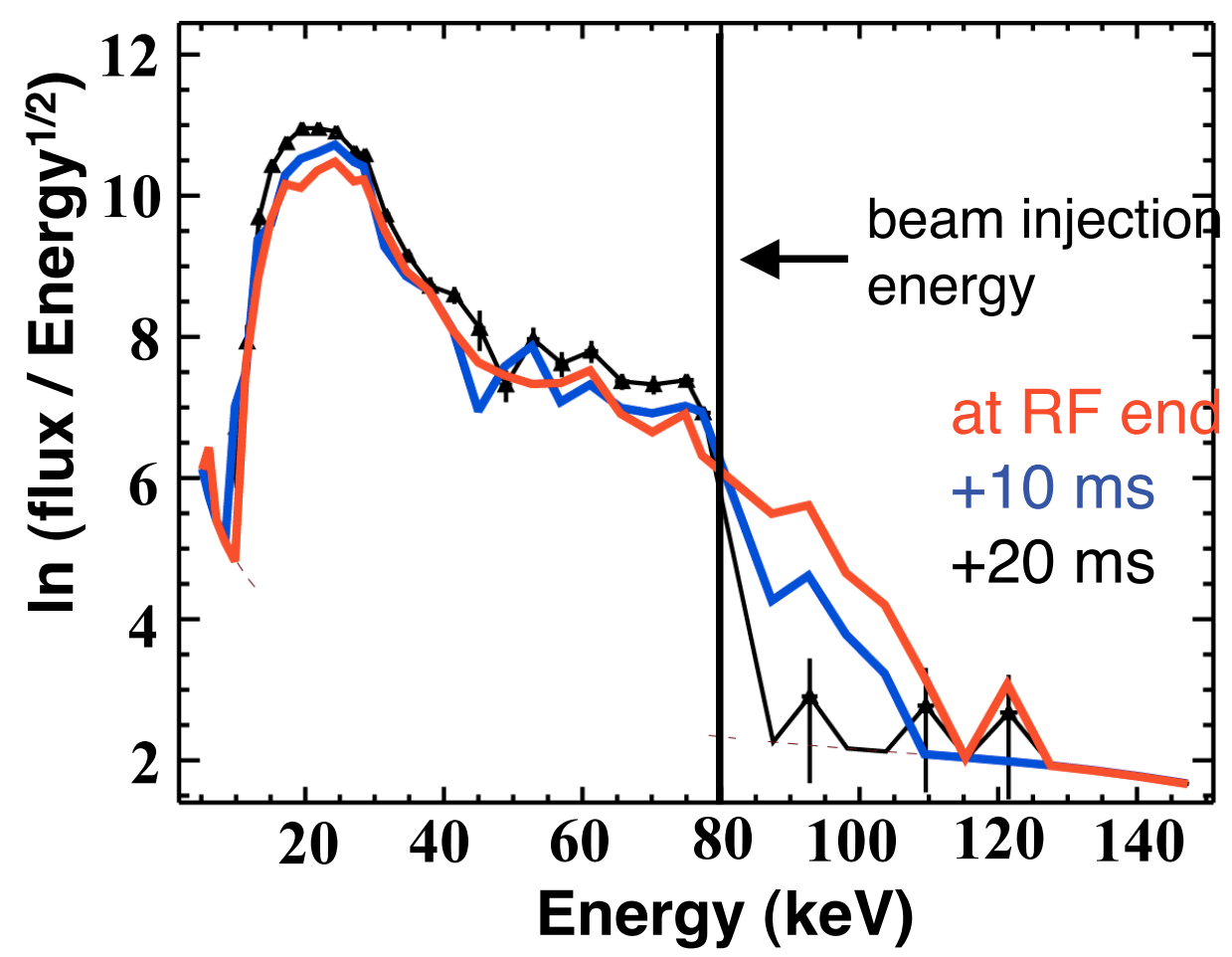

Figure 6 


\section{External Distribution}

Plasma Research Laboratory, Australian National University, Australia

Professor I.R. Jones, Flinders University, Australia

Professor João Canalle, Instituto de Fisica DEQ/IF - UERJ, Brazil

Mr. Gerson O. Ludwig, Instituto Nacional de Pesquisas, Brazil

Dr. P.H. Sakanaka, Instituto Fisica, Brazil

The Librarian, Culham Laboratory, England

Mrs. S.A. Hutchinson, JET Library, England

Professor M.N. Bussac, Ecole Polytechnique, France

Librarian, Max-Planck-Institut für Plasmaphysik, Germany

Jolan Moldvai, Reports Library, MTA KFKI-ATKI, Hungary

Dr. P. Kaw, Institute for Plasma Research, India

Ms. P.J. Pathak, Librarian, Insitute for Plasma Research, India

Ms. Clelia De Palo, Associazione EURATOM-ENEA, Italy

Dr. G. Grosso, Instituto di Fisica del Plasma, Italy

Librarian, Naka Fusion Research Establishment, JAERI, Japan

Library, Plasma Physics Laboratory, Kyoto University, Japan

Research Information Center, National Institute for Fusion Science, Japan

Dr. O. Mitarai, Kyushu Tokai University, Japan

Library, Academia Sinica, Institute of Plasma Physics, People's Republic of China

Shih-Tung Tsai, Institute of Physics, Chinese Academy of Sciences, People's Republic of China

Dr. S. Mirnov, TRINITI, Troitsk, Russian Federation, Russia

Dr. V.S. Strelkov, Kurchatov Institute, Russian Federation, Russia

Professor Peter Lukac, Katedra Fyziky Plazmy MFF UK, Mlynska dolina F-2, Komenskeho Univerzita, SK-842 15 Bratislava, Slovakia

Dr. G.S. Lee, Korea Basic Science Institute, South Korea

Institute for Plasma Research, University of Maryland, USA

Librarian, Fusion Energy Division, Oak Ridge National Laboratory, USA

Librarian, Institute of Fusion Studies, University of Texas, USA

Librarian, Magnetic Fusion Program, Lawrence Livermore National Laboratory, USA

Library, General Atomics, USA

Plasma Physics Group, Fusion Energy Research Program, University of California at San Diego, USA

Plasma Physics Library, Columbia University, USA

Alkesh Punjabi, Center for Fusion Research and Training, Hampton University, USA

Dr. W.M. Stacey, Fusion Research Center, Georgia Institute of Technology, USA

Dr. John Willis, U.S. Department of Energy, Office of Fusion Energy Sciences, USA

Mr. Paul H. Wright, Indianapolis, Indiana, USA 
The Princeton Plasma Physics Laboratory is operated by Princeton University under contract with the U.S. Department of Energy.

\author{
Information Services \\ Princeton Plasma Physics Laboratory \\ P.O. Box 451 \\ Princeton, NJ 08543
}

Phone: 609-243-2750

Fax: 609-243-2751

e-mail: pppl_info@pppl.gov

Internet Address: http://www.pppl.gov 